\title{
Using Innovative and Scientifically-Based Debate to Build e-Learning Community
}

\author{
Cheng-Chia (Brian) Chen and Karen Swan \\ University of Illinois Springfield
}

\begin{abstract}
The research described in this article explored the efficacy of a novel teaching strategy to recreate classroom debates online. Using a structured approach and collaborative group work, the researchers developed an approach that students found very useful in six different dimensions: enhancement of active learning, critical thinking, interaction and engagement among students and between the instructor and students, the usefulness of Google Docs for student collaboration, Google Docs usefulness to enhance learning, and willingness to use Google Docs for future collaborative projects. The total subjects $(n=52)$ consisted of two groups of undergraduate and graduate students from health-related online courses. The first group contained 25 students who were admitted to $100 \%$ online academic programs. The second group consisted of 27 students who were admitted to on-campus academic programs with limited on-line course taking experiences. The research also explored possible differences in perceptions stemming from students' familiarity with online learning by comparing the perceptions of students enrolled in only online classes with those of students enrolled in primarily on-ground classes. No significant differences in any of the variables were found, indicating the efficacy of the approach for all students.
\end{abstract}

Keywords: online debate, e-learning community, active learning, critical thinking, online teaching, online learning

Chen, C.C. \& Swan, K. (2020). Using innovative and scientifically-based debate to build elearning community. Online Learning, 24(3), 67-80. https://doi.org/10.24059/olj.v24i3.2345

\section{Using Innovative and Scientifically-Based Debate to Build e-Learning Community}

With the whole world under the threat of the novel coronavirus (COVID-19), vast numbers of schools and institutions of higher education have been experiencing a sudden need to initiate or enhance online teaching and learning. Online education is a growing field that has the potential to enhance learning outcomes by offering more teaching and learning flexibility. More than $30 \%$ of students took at least one online course in Fall 2016 (Jiang, Ballenger, \& Holt, 2019; Seaman, Allen, \& Seaman, 2018). Moreover, an overwhelming majority of students (69\%) were taking at least one online course at public institutions (Seaman et al., 2018). With the stay-at-home orders 
issued in attempts to deal with the COVID-19 pandemic, it is more important than ever to enhance online education pedagogies.

Indeed, a persistent challenge of online teaching is to successfully adjust on-campus teaching strategies for online course delivery methods. The research literature provides evidence that online courses can be as effective as face-to-face courses when the delivery methods are welldesigned to accommodate students' needs (Driscoll et al., 2012; Hadidi \& Sung, 2000; Keengwe, Onchwari, \& Agamba, 2014; Shea \& Swan, 2020). With proper development and the implementation of engaging online learning activities, students can interact with their instructors and classmates using a variety of online technologies such as Zoom video conferences, Short Message Service (SMS), and Google Docs (Moore, 2016; Zhou, Simpson, \& Domizi, 2012). Such studies have shown that simply asking students to address the instructors' questions may have limited learning effectiveness (Wolfe \& Uribe, 2020). To resolve this issue, the establishment of well-crafted student interactive activities that leads to a sound e-learning community can make a large difference in learning from ordinary online discussions. Educators have to use online teaching techniques appropriately with good designs to meet and surpass the effectiveness of faceto-face classes.

The advantages of the online learning format may include higher flexibility of course schedules, a student-centered approach with, to a greater or lesser extent, self-paced learning, and the capability to fulfill the needs of students with a wide range of learning styles. Online discussion, moreover, allows more time for reflection and values the voices of all students. On the other hand, online discussion does not allow for the immediate negotiation of meaning possible in face-to-face discussions. Other challenges may involve more limited means for communication, and the limitations of technology affordances (Ascough, 2002; Lall \& Singh, 2020). To resolve these drawbacks, the establishment of structured interaction is strongly needed.

Educational debate activities have long been used as an active learning tool for students and as a format to encourage collaborative learning (Elliot, 1993; Peasah \& Marshall, 2017; Roy, 2012; Zare \& Othman, 2013). Both active learning and collaborative activities have been shown to increase student performance (Freeman et al., 2014). Debates can be especially effective in courses where certain issues or topics do not have right or wrong answers. Effective debates can increase students' critical thinking and communication skills, encourage collaboration, and enhance engagement among students as well as between students and instructors (Bradshaw, 2017; Darby, 2007; Mitchell, 2019).

Traditionally, educational debates are held in face-to-face classes with one person in affirming a position and another person arguing against it. Face-to-face debates can also be expanded to group debates with several students in the affirmative and negative groups. For some disciplines such as sociology, public health, nursing, and pharmacology, students and professionals in their fields may need to argue their positions concerning controversial social phenomena or issues that might not have a commonly accepted conclusion (e.g., Is obesity a disease?). In these settings, students often use verbal communications to debate their positions.

If we move this traditional format directly to a remote setting with a synchronous approach, it will create notable challenges and barriers to operating the debate activity smoothly. For example, a high-speed internet connection is often required for all students to ensure constant online connectivity without lagging, delay, or disconnection. In addition, it is challenging to provide an ideal debating environment for online students due to the lack of face-to-face class meetings. 
Therefore, an innovative design of asynchronous online group debates could be a valuable and practical vehicle to enhance interactions among online students and instructors, and so contribute to achieving excellence in student learning outcomes.

Furthermore, how would an innovative online group debate connect to the establishment of an e-learning community? It has to be designed in line with the three dimensions of an ideal elearning community ( $\mathrm{Tu} \&$ Corry, 2002). The first dimension involves instructions with interactivity, community engagement, collaboration, and moderation. The second dimension is social interaction to develop the social context, socio-cultural, and socio-cognitive environment. The third dimension is the technology with the capability to trigger opportunities for knowledge construction. Our online group debates were designed to address these three dimensions and aim at building a sound e-learning community.

In the present study, the researchers used a variety of innovations that transform benefits from traditional one-time synchronous debate to asynchronous 'online group debates' in a 16week online course. This online scientifically-based group debate project counted $20 \%$ of the total grade. There was another collaborative project (i.e., group video presentation) around the end of the semester, which constituted another $20 \%$ of the total grade. Other student learning assessments included individual assignments (40\%) and a final exam (20\%) with questions such as true/false and multiple-choice questions. The specific learning objectives for the online group debates were to be able to: (1) identify and discuss the determinants of obesity; (2) discuss the medical and psychosocial context of obesity; (3) critique and analyze interventions for obesity prevention and control using scientific evidence.

The online group debate topics were adapted from the required course textbook (Rossen \& Rossen, 2012) - "Obesity 101," and the research article written by Cheng-Chia (Brian) Chen: "Longitudinal State-Level effects on change in body mass index among middle-aged and older adults in the USA." This research discussed the determinants of obesity by analyses of large nationally representative data (Chen, Seo, \& Lin, 2018). The three group debate topics were selected because they are debatable and controversial public health issues without clear-cut answers. The selected topics were:

- Is obesity a disease?

- Should physical education be mandatory?

- Should pouring rights contracts (i.e., availability of soft drink in schools) be supported by school administrators?

The grading criteria for the group debate's final product are as follows (each criterion -15 points):

1. Respect for Other Team Members (Were all statements and responses respectful and appropriate?)

2. Information (Was information presented in this debate clear, accurate, and thorough?)

3. Rebuttal (Were all counter-arguments accurate, relevant, and strong?)

4. Use of Facts/Statistics/Literature (Was every major point well supported with several reliable and relevant facts, statistics, and/or peer-reviewed literature?) 
5. Organization (Were all arguments clearly tied to an idea [premise] and organized in a tight and logical fashion?)

6. Understanding of Debating Topic (Did all team members clearly understand the topic in depth and present their information professionally and convincingly?)

Each online group debate involved two teams of 3 to 4 students. All group members were expected to participate in research, development, and presentation of their group's debate position. During week 1, the instructor asked students to post a short biography and a picture of themselves on the Blackboard Learning Management System (LMS). During the first four weeks, students were assigned to their groups. Each group signed up for a controversial debate topic in public health on a first-come, first-served basis, specifying their desired debate topic and position (i.e., affirmative or negative). Each group also had to complete team-building exercises including comprehensive discussions of the group's communication methods, time, and frequencies relative to each week's goals. Team leaders were elected and were required to report teams' progress to the instructor each week. The entire debate details on team-building exercises and timeline of debate related activities are summarized below and in Table 1.

Each debate project contained the following components:

1. Team Building Activities and Preparation of Collaborative Essay Writing for the Debate: All students introduced themselves on the Discussion Board on the LMS and they were required to take Google Docs and research skills training lessons. Then, they needed to get familiar with each other and elect a team leader. In addition, students were required to attend the "Group Work Q \& A" online workshop held by the instructor via 'Google Meet.' More importantly, they had to complete a very comprehensive "Communication Work Plan" through Google Docs.

2. Pre-debate Activities: Students collected relevant resources and developed draft statements using Google Docs. The instructor gave timely comments and worked closely with students for multiple revisions.

- Part 1-"Position Statement and Three Supporting Arguments" Essay: The position statement and support arguments included a discussion of the debate issue, a detailed description of the group's perspective, an overview of the upcoming arguments, and three different support arguments. Students worked in groups to create an evidencebased group position statement and wrote it in Google Docs. Only peer-reviewed journal articles were to be used.

- Part 2- "Rebuttal" Essay: Each group then created and posted a group rebuttal statement responding to the other side's argument and providing further evidence in support of their original case statement. Only peer-reviewed journal articles were to be used.

- Part 3- "Response to Rebuttal and Position Summary" Essay: Students were then required to write a summation of their group's perspective, arguments, response to the rebuttal, as well as closing statements providing scientific evidence and arguments supporting their conclusion. Only peer-reviewed journal articles were to be used. 
3. Final Product: Each group has to submit three final versions of their debate 'essays' on Blackboard - (a) "Part 1: Position Statement and Three Supporting Argument" essay (about 2,000 words); (b) "Part 2: Rebuttal " essay (about 2,000 words); and (c) "Part 3: Response to Rebuttal and Position Summary" essay (about 1,000 words).

4. Peer Evaluation and Reflection: Students were asked to evaluate their participation and contributions to the group, as well as that of their group members.

5. Audience Opinion Essay: Each audience member (non-participant in a particular debate) was required to provide comments in an essay format for both debate teams and share their own opinions. Students also voted on the winning team in each debate topic. as follows:

Seven innovative designs and delivery approaches were employed in online debate projects

1. During the first four weeks, students had four weeks to know each other better. Debate teams worked together to choose either positive and negative views (on a first-come, firstchoice basis) concerning a specific public health argument or policy. In week 7 , their comradery was further facilitated through 'Google Meet' online video meetings with the instructor. They then worked in groups to collaboratively write several essays - position statement, three support arguments, rebuttal, responses to rebuttals, and position summary - to support their assigned perspectives for the debates.

2. The debates lasted for fourteen weeks with the asynchronous approach instead of debating several arguments in just one class.

3. Students had to use learned knowledge in the first seven weeks and apply the concepts to write collaborative essays as a form of online debate activities instead of just using their personal opinions for debates.

4. Students were trained to use Google Docs and library database search for peer-reviewed resources in the first four weeks, and then utilize Google Docs to write and edit their essays with rich communication activities among the team members and prompt guidance from the instructor.

5. Students needed to elect a team leader with responsibilities for assigning the workload evenly and providing weekly work progress reports to the instructor.

6. The team leaders worked closely with the instructor and group members to set up detailed weekly goals, group internal deadlines, and timelines throughout the entire debate preparation and writing process.

7. Students were required to mutually agree to use the same SMS (e.g., text-message, "Group $\mathrm{Me}$," or WhatsApp) to communicate with each other in addition to email communications. 
Table 1

Timeline for Debate-Related Activities

Online Group Debate Project Required Task

Team-Building Self-Introduction by all students and Preparation of Collaborative Essay Writing for the Debate

Pre-Debate Activities

Final Product

Peer Evaluation $\&$ Reflection

All debate teams sign up for the desired topic. collaboration to the instructor. Plan" via Google Docs.

Meeting with the instructor via

Google Meet.

Pre-debate Writing Activities -

resources (about 2,000 words).

Pre-debate Writing Activities -

resources (about 2,000 words).

Pre-debate Writing Activities -

resources (about 1,000 words).

Pre-debate Writing Activities-

$1-3$ based on the instructor's

guidance and suggestions.

related essays (Part 1 to 3 ) on

Blackboard Discussion Board

available to the entire class.

Each student submits the peer
Complete Google Apps and research

skill training. Then, take a timed quiz.

Create teams, select team leaders, and get familiar with each team member.

Team leaders report the progress of

Complete "Communication Work

Attend "Group Work Q \& A" Online

Develop "Part 1: Position Statement

and Three Arguments" Essay via

30 points

Google Docs based on peer-reviewed

Develop "Part 2: Rebuttal" Essay via

Google Docs based on peer-reviewed

30 points

Develop "Part 3: Response to Rebuttal

and Position Summary" Essay via 30 points

Google Docs based on peer-reviewed

Revisions for the final version of Part

N/A

Post all revised and completed debate-

90 points (with Grading

Rubric)

evaluation with the reflection of the 45 points

collaboration.

Write "Audience Opinion Essay" \&

vote the winning team in each

debating topics.

90 points

N/A

N/A

N/A

50 points

N/A

poins

N/A
Week

Evaluation Weight (20\% of the Course Total Grade)

30 points $\begin{array}{llllllllllllll}2 & 3 & 4 & 5 & 6 & 7 & 8 & 9 & 10 & 11 & 12 & 13 & 14\end{array}$

$\mathrm{X}$

$\mathrm{X}$

$\mathrm{X}$

\begin{tabular}{l|l|l}
$\mathrm{X}$ & $\mathrm{X}$ \\
\end{tabular}

$x$

$\begin{array}{llllllllllllll}X & X & X & X & X & X & X & X & X & X & X\end{array}$

\begin{tabular}{l|l|l}
$\mathrm{X}$ & $\mathrm{X}$ & $\mathrm{X}$
\end{tabular}

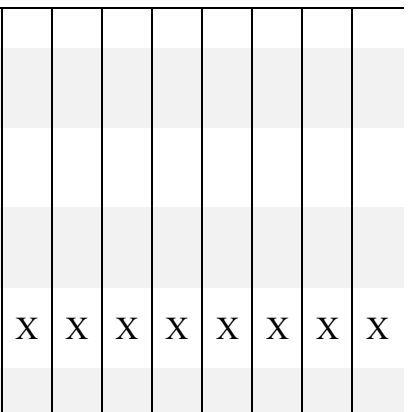

$\mathrm{X}$

$\mathrm{X} X$

$\mathrm{X}$

$\mathrm{X}$

$\mathrm{X}$

$\mathrm{X}$ 
One of the most interesting innovations employed in the project was the requirement to use Google Docs as the students' collaboration tool to write up all elements of the online group debate. Google Docs is a free and convenient real-time document authoring and collaboration tool, which has been reported as a potentially effective vehicle for team building and teamwork (Mitchell, 2019; Moore, 2016; Zhou et al, 2012). It can allow up to 50 people to edit a Word document at the same time. During the collaborative writing process, users can see each other's changes instantaneously and all editing histories will be recorded permanently. Students and instructors can take advantage of Google Docs' 'History' function to resume any version of the entire editing history. The contents in Google Docs are automatically saved in real-time and collaborators usually do not have to worry about the loss of their teamwork. Another important creative piece for this setting is that instructors and students are capable to use the relatively new 'Chat' function during the collaborative writing process, which is extremely useful for teachers to give just-intime feedback and writing suggestions, and for group debate members to exchange opinions and resources (see Figure 1). Moreover, when students are using Google Docs, SMS, emails, and following the debate instructional guidelines/policies, it establishes an engaged learning environment that covers all aforementioned key components of an excellent e-learning community.

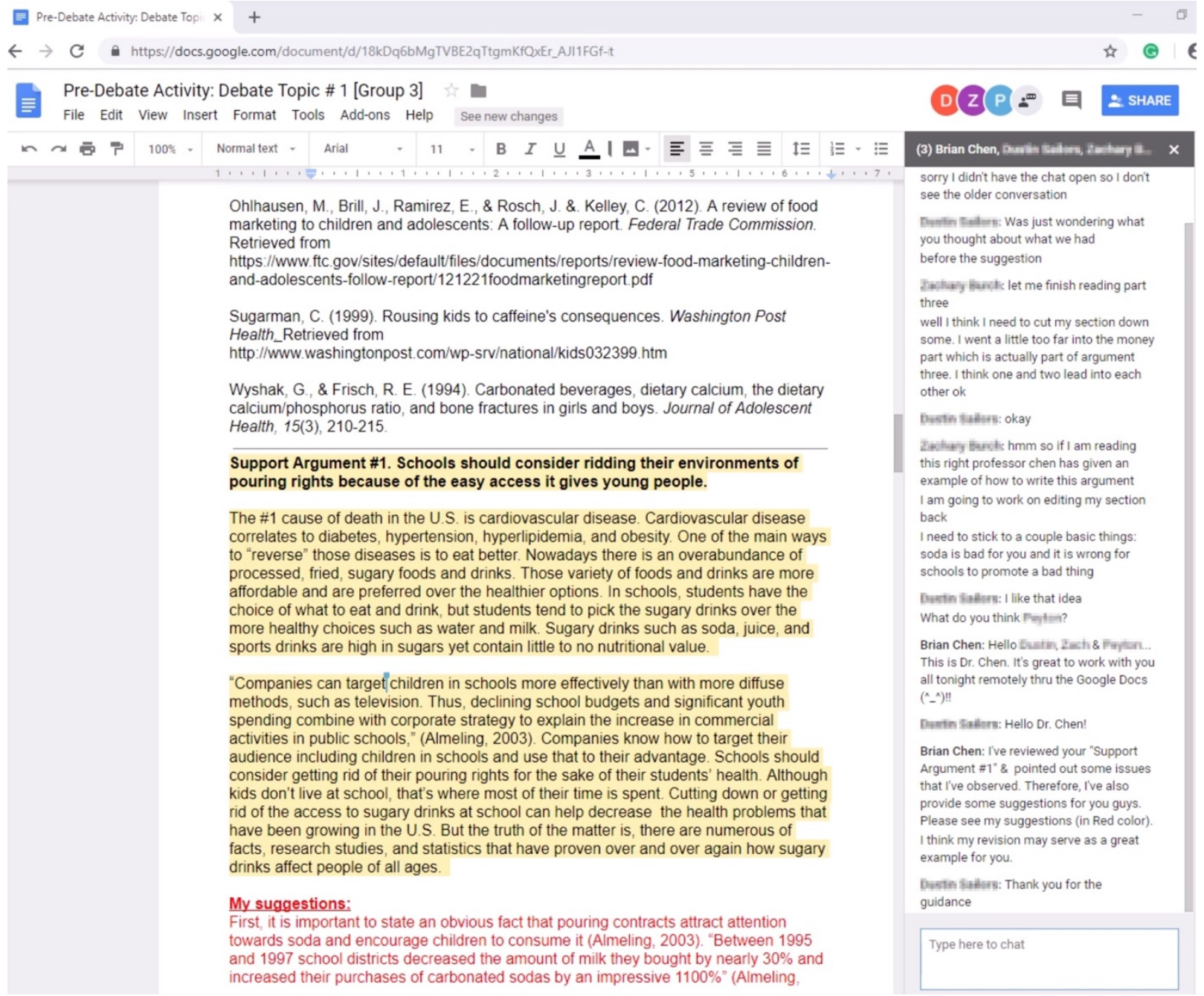

Figure 1. Screenshot of Google Docs Collaborative Writing Process with the Instant Feedback from the Instructor 
The first aim of the study was to explore the effectiveness of online group debates in an online health-related course by examining students' perceptions of their effectiveness/usefulness. The second research aim was to investigate whether students' perceived utility of the online debate format differed between students enrolled in a 100\% online academic program (Group 1) and students enrolled in an on-campus academic program (Group 2) with very limited exposure to online learning experiences.

\section{Methods}

\section{Subjects and Sampling Methods}

The present study evaluated students' perceived usefulness/effectiveness of their experiences in online group debates and the required collaborative writing in Google Docs. This research project was approved by the IRB Office. Students were given consent forms before entering the online survey (Zhou et al., 2012) at the end of each semester. The study participants were 52 students who enrolled in an online health elective course at a Midwestern university from 2016 to 2019. To answer the second aim of the study, these 52 students were separated into the two groups. The number of students (sample size $=25$ ) who were admitted to a $100 \%$ online academic program (Group 1) was close to the number of students in Group 2 (sample size $=27$ ) who were admitted to an on-campus academic program. Among all subjects, there were 47 undergraduate students (juniors and seniors only) and five graduate students. Around $69 \%$ of the students were females and $62 \%$ of them were under 24 years old (see Table 1).

Table 2

Descriptive Statistics $(n=52)$

\begin{tabular}{lcc}
\hline & $\boldsymbol{n}$ & $\mathbf{\%}$ \\
\hline Gender & & \\
$\quad$ Female & 36 & 69.2 \\
$\quad$ Male & 16 & 30.8 \\
Student Status & & \\
$\quad$ Graduate & 5 & 9.6 \\
$\quad$ Undergraduate (Junior \& Senior) & 47 & 90.4 \\
Age & & \\
$\quad<24$-year-old & 32 & 61.5 \\
$\quad 2$ 24-year-old & 20 & 38.4 \\
Students' Admission Status & & 48.1 \\
$\quad$ 100\% Online Program (Group 1) & 25 & 51.9 \\
$\quad$ On-Campus Program (Group 2) & 27 & \\
\hline
\end{tabular}

\section{Study Variables}

Basic demographic information such as gender and age was included in the online survey. Subjects were also asked whether their admission status was primarily online or on-ground. Six other study variables included: 
1. student perceptions of the enhancements of active learning,

2. student perceptions of the enhancements to critical thinking,

3. student perceptions of the enhancements of class interaction and engagement from their online group debate experiences,

4. student perceptions of the usefulness of the collaborative writing tool (Google Docs),

5. student perceptions of the usefulness of Google Docs in improving learning outcomes, and

6. students' reported willingness to use Google Docs as a collaboration tool in the future. Five-point Likert scales were used to measure the strength of agreement or disagreement (i.e., $1=$ strongly disagree and $5=$ strongly agree) with the survey questions.

\section{Data Analysis}

Before performing the comparisons of students' perceived utility of the online debate and Google Docs, the parametric assumptions of the study variables (i.e., normality and homogeneity of variance) were tested between the online students and the primarily on-ground students. Since the normality was not satisfied and the homogeneity of variance was met between groups, Welch's $t$-tests were conducted for all six study variables. The purpose of Welch's $t$-tests was to evaluate whether differences existed between students in Group 1 and Group 2. The nonparametric MannWhitney-Wilcoxon test was not performed because Type I error may be inflated when it is employed and there has been no optimal procedure to deal with tied ranks (Hahs-Vaughn \& Lomax, 2020, pp. 234-235).

\section{Results}

Students' perceptions of the enhancement of active learning, critical thinking, as well as interaction and engagement are illustrated in Figure 2. Nearly $87 \%$ of students agreed that the online group debate project enhanced their active learning, and more than half $(>50 \%)$ of the students strongly agreed with that statement. Approximately $81 \%$ of the students agreed that the online group debate had increased their skills in critical thinking ( $48.1 \%$ of students reported that they strongly agreed with this statement). Additionally, around $90 \%$ of students agreed that the online group debate improved the interaction and engagement among the students and between the instructor and students.

Figure 3 demonstrates student perceptions of the usefulness of Google Docs for collaboration and learning, and their willingness to deploy Google Docs as a collaborative tool in the future. Approximately $85 \%$ of students valued Google Docs as a useful tool for team-based projects. Nearly $77 \%$ of students agreed that the use of Google Docs enhanced their learning. Finally, approximately $69 \%$ of students reported that they would consider using Google Docs for collaborative tasks in the future. 


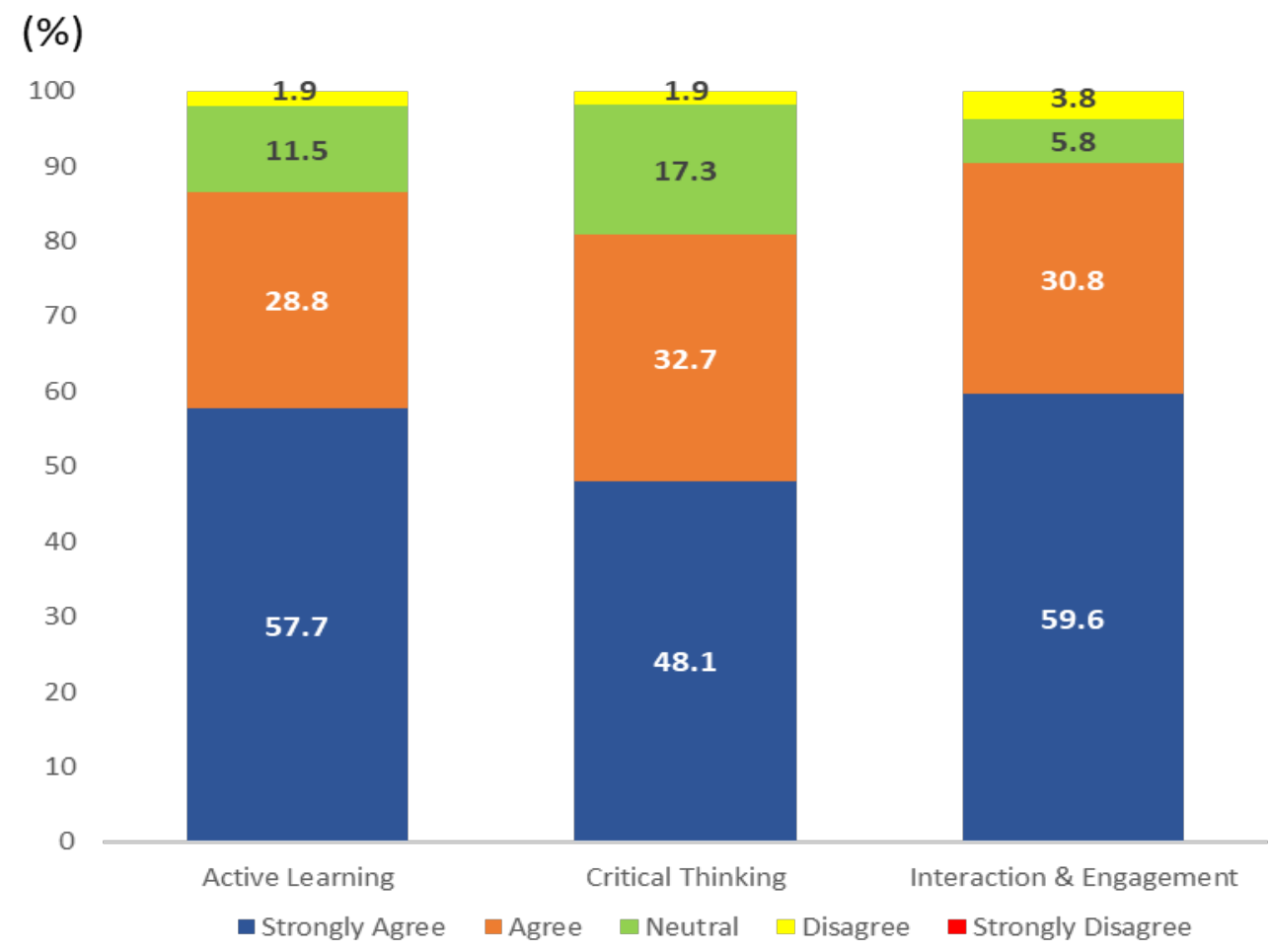

Figure 2. Students' Perceptions of the Enhancements to Active Learning, Critical Thinking, and Engagement from Their Online Group Debate Experiences.

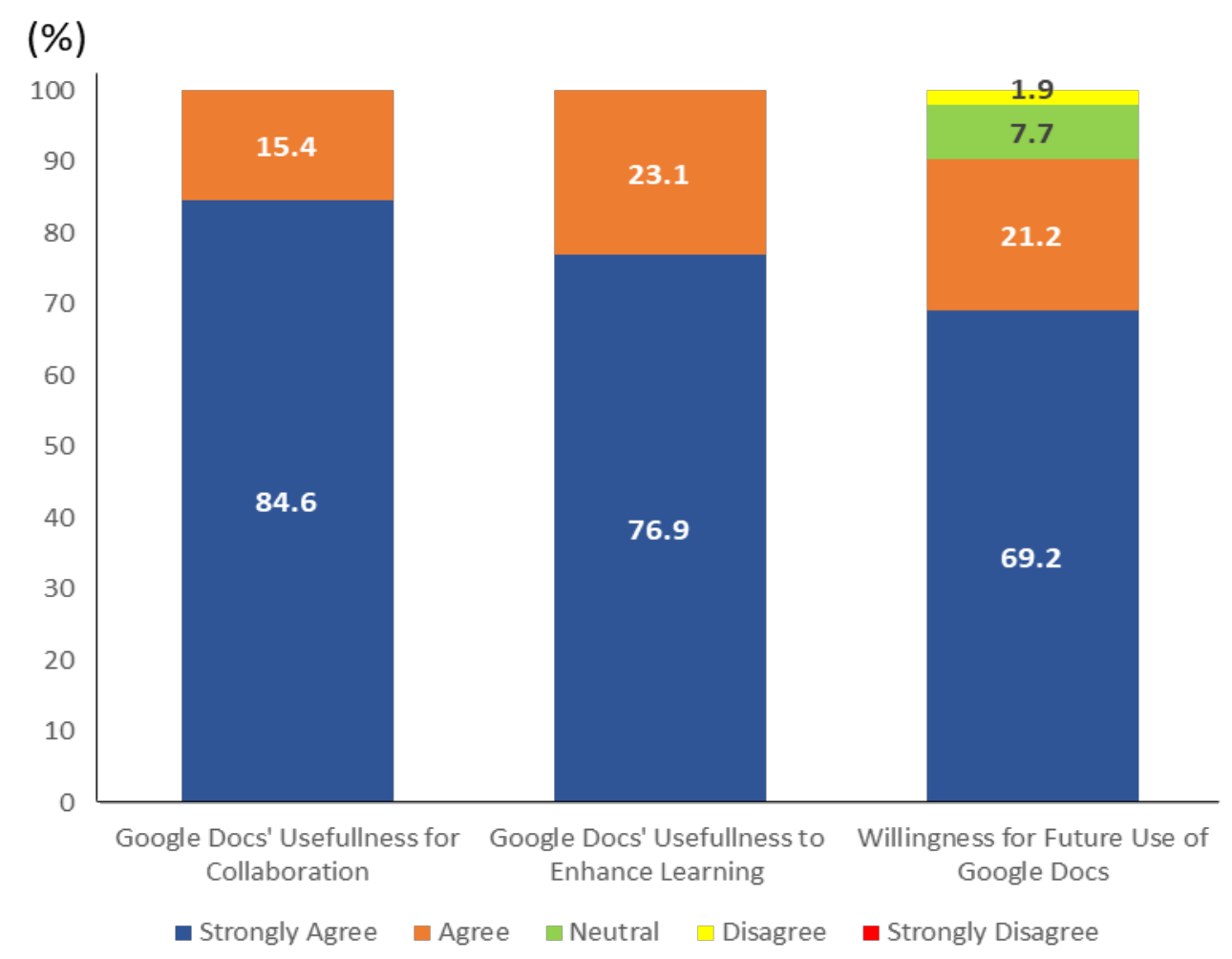

Figure 3. Students' Perceptions towards the Usefulness of Google Docs and Willingness to Use It Again in the Future. 
Table 3 presents the mean values for each of the six study variables for students in the online and on-ground groups. Welch's $t$-tests were used to compare the groups on each of these. The results of Welch's $t$-tests were not statistically significant for any of the variables. The test statistics and $p$-values are reported in Table 3.

Table 3

Welch's t-test that Compared Study Variables between Group 1 and Group 2

\begin{tabular}{|c|c|c|c|c|c|c|}
\hline & \multicolumn{2}{|c|}{$\begin{array}{l}\text { Students in a } 100 \% \\
\text { Online Program } \\
\text { (Group 1) }\end{array}$} & \multicolumn{2}{|c|}{$\begin{array}{l}\text { Students in an } \\
\text { On-Campus Program } \\
\text { (Group 2) }\end{array}$} & \multirow[b]{2}{*}{$\begin{array}{l}\text { Welch's } \\
\text { Test }\end{array}$} & \multirow[b]{2}{*}{$p$-value } \\
\hline & $M$ & $S D$ & $\boldsymbol{M}$ & $S D$ & & \\
\hline Active Learning & 4.48 & 0.71 & 4.37 & 0.84 & 0.26 & 0.61 \\
\hline Critical Thinking & 4.32 & 0.69 & 4.22 & 0.93 & 0.19 & 0.67 \\
\hline $\begin{array}{l}\text { Interaction \& } \\
\text { Engagement }\end{array}$ & 4.36 & 0.91 & 4.56 & 0.64 & 0.80 & 0.38 \\
\hline $\begin{array}{l}\text { Google Docs' Usefulness } \\
\text { for Collaboration }\end{array}$ & 4.80 & 0.41 & 4.89 & 0.32 & 0.76 & 0.39 \\
\hline $\begin{array}{l}\text { Google Docs' Usefulness } \\
\text { to Enhance Learning }\end{array}$ & 4.72 & 0.46 & 4.81 & 0.40 & 0.63 & 0.43 \\
\hline $\begin{array}{l}\text { Willingness for Future } \\
\text { Use of Google Docs }\end{array}$ & 4.48 & 0.82 & 4.67 & 0.62 & 0.84 & 0.36 \\
\hline
\end{tabular}

\section{Discussion}

The findings indicate that online debate may be as effective as the debate in the face-toface classroom. High percentages of students reported very positive perceptions of the group debate's influence on their active learning, critical thinking, and interaction with their classmates and the instructor. These findings are consistent with previous studies in the on-campus setting (Kennedy, 2007; Roy, 2012; Zare et al., 2013), as well as in the online courses (Lin \& Crawford, 2007; Richardson \& Ice, 2010; Stephens \& Roberts, 2017; Stockleben et al., 2017). Moreover, comparisons between online students and students enrolled in primarily on-ground classes reveal that their perceptions of the utility of group debates and Google Docs were statistically similar. This suggests that student perceptions were not affected by their familiarity or lack thereof with the online environment. It is an important contribution to the literature of online learning and instruction design for educational debates.

After graduation, students often will need to make decisions based on scientific evidence and justify a variety of situations with critical thinking. Besides, slick and smooth interaction skills could be very powerful in achieving productive and efficacious collaboration. Thus, online group debates could be a valuable experience to help students develop these skills. The group debating process in the study also involved the collaborative use of Google Docs which may help prepare students for teamwork and collaboration skills. Specifically, collaboration with peers facilitated by the instructor made what might have been a difficult and anxiety-producing exercise instead of positive and rewarding. The findings should encourage educators to change the style of debate in 
their classes and apply those innovative approaches to improve students' understanding of practical problem-solving.

The results of this study must be interpreted in light of several limitations. First, the Hawthorne effect may have resulted in somewhat higher ratings for the online debate format. Second, the study investigated students enrolled in a health-related course and may not be generalizable beyond that context. Third, the perceived effectiveness of Google Docs might not reflect the real usability of the collaborative tool. Finally, generalizability might be an issue due to the sample size and type of courses.

One of the directions for further research may be the enhancement of subject recruiting to increase the sample size, which could increase the generalizability. Researchers may want to recruit subjects from different disciplines as well. Online learning scholars may consider using direct measurement data of critical thinking. The purpose is to determine if this skill can be improved with participation in online group debates. Besides, future research may look up more data from more graduate students, who only made up about $10 \%$ of subjects in the present study. Finally, it would be worthwhile to measure what students think about their time spent on the debate project (e.g., reasonable, too long, or too short).

In summary, asynchronous online group debates can be utilized to build effective elearning communities and applied to different disciplines and curriculums. With an almost semester-long and structured debate project, students feel that they belong to an e-learning community that fosters interactive collaborations and engagement with proper monitoring system led by the team leaders and instructor. It also increases students' exposure to online social interactions and affords multiple opportunities for knowledge acquisition through technology. Finally, our innovations overcame several disadvantages of online teaching and created many teamwork opportunities to enrich students' online learning experiences. 


\section{References}

Ascough, R. S. (2002). Designing for online distance education: Putting pedagogy before technology. Teaching Theology \& Religion, 5(1), 17-29.

Bradshaw, M. J. (2017). Debate as a teaching strategy. In M. J. Bradshaw \& B. L. Hultquist (Eds.), Innovative teaching strategies in nursing and related health professions. Jones \& Bartlett Learning.

Chen, C. C., Seo, D. C., \& Lin, H. C. (2018). Longitudinal state-level effects on change in body mass index among middle-aged and older adults in the USA. Health Education Journal, 77(1), 59-72.

Darby, M. (2007). Debate: A teaching-learning strategy for developing competence in communication and critical thinking. Journal of Dental Hygiene, 81(4), 78-1-78-10.

Driscoll, A., Jicha, K., Hunt, A. N., Tichavsky, L., \& Thompson, G. (2012). Can online courses deliver in-class results? A comparison of student performance and satisfaction in an online versus a face-to-face introductory sociology course. Teaching Sociology, 40(4), 312-331.

Elliot, L. B. (1993). Using debates to teach the psychology of women. Teaching of Psychology, 20(1), 35-38.

Freeman, S., Eddy, S. L., McDonough, M., Smith, M. K., Okoroafor, N., Jordt, H., \& Wenderoth, M. P. (2014). Active learning increases student performance in science, engineering, and mathematics. Proceedings of the National Academy of Sciences, 111(23), $8410-8415$.

Hadidi, R., \& Sung, C. H. (2000). Pedagogy of online instruction: Can it be as good as face-toface? Americas Conference on Information Systems (AMCIS) 2000 Proceedings, 288, 20612065.

Hahs-Vaughn, D. L. \& Lomax, R. G. (2020). An introduction to statistical concepts (4th ed.). Routledge.

Jiang, M., Ballenger, J., \& Holt, W. (2019). Educational leadership doctoral students' perceptions of the effectiveness of instructional strategies and course design in a fully online graduate statistics course. Online Learning, 23(4), 296-312.

Keengwe, J., Onchwari, G., \& Agamba, J. (2014). Promoting effective e-learning practices through the constructivist pedagogy. Education and Information Technologies, 19(4), 887898.

Kennedy, R. (2007). In-class debates: Fertile ground for active learning and the cultivation of critical thinking and oral communication skills. International Journal of Teaching \& Learning in Higher Education, 19(2), 183-190.

Lall, S., \& Singh, N. (2020). CoVid-19: Unmasking the new face of Education. International Journal of Research in Pharmaceutical Sciences, 11(Suppl. 1), 48-53. https://doi.org/10.26452/ijrps.v11iSPL1.2122

Lin, S. J., \& Crawford, S. Y. (2007). An online debate series for first-year pharmacy students. American Journal of Pharmaceutical Education, 71(1, Article 12), 1-8. 
Mitchell, E. T. (2019). Using debate in an online asynchronous social policy course. Online Learning, 23(3), 21-33.

Moore, C. (2016). The future of work: What Google shows us about the present and future of online collaboration. Tech Trends, 60(3), 233-244.

Peasah, S. K., \& Marshall, L. L. (2017). The use of debates as an active learning tool in a college of pharmacy healthcare delivery course. Currents in Pharmacy Teaching and Learning, 9(3), 433-440.

Richardson, J. C., \& Ice, P. (2010). Investigating students level of critical thinking across instructional strategies in online discussion. The Internet and Higher Education, 13(1-2), 5259.

Rossen, L. M., \& Rossen, E. A. (2012). Obesity 101. Springer.

Roy, D. P. (2012). Promoting active learning of ethical issues in marketing communications using debates. Marketing Education Review, 22(1), 73-76.

Seaman, J. E., Allen, I. E., \& Seaman, J. (2018). Grade increase: Tracking distance education in the United States. https://onlinelearningsurvey.com/reports/gradeincrease.pdf

Shea, P., \& Swan, K. (2020). What e-learning leaders should know about learning effectiveness. In G. Miller, \& K, Ives (Eds.), Leading the e-learning transformation of higher education: Leadership strategies for the next generation (2nd ed., pp. 75-95). Stylus.

Stephens, G. E., \& Roberts, K. L. (2017). Facilitating collaboration in online groups. Journal of Educators Online, 14(1), 1-16.

Stockleben, B., Thayne, M., Jäminki, S., Haukijärvi, I., Mavengere, N. B., Demirbilek, M., \& Ruohonen, M. (2017). Towards a framework for creative online collaboration: A research on challenges and context. Education and Information Technologies, 22(2), 575-597.

Tu, C. H., \& Corry, M. (2002). eLearning communities. Quarterly Review of Distance Education, 3(2), 207-218.

Wolfe, K. A., \& Uribe, S. N. (2020). What we wish we would have known: Tips for online instructors. College Teaching, 1-3. doi: 10.1080/87567555.2020.1711701

Zare, P., \& Othman, M. (2013). Classroom debate as a systematic teaching/learning approach. World Applied Sciences Journal, 28(11), 1506-1513.

Zhou, W., Simpson, E., \& Domizi, D. P. (2012). Google Docs in an out-of-class collaborative writing activity. International Journal of Teaching and Learning in Higher Education, 24(3), 359-375. 